\title{
The Advice of Provision and Circulation of Basic Agricultural Product Under 2019 Novel Coronavirus in China
}

\author{
Xiaoshun Qin ${ }^{1}$, Taopeng Zhang ${ }^{2}$ \& Victor M. Mmbengwa ${ }^{3,4}$ \\ ${ }^{1}$ Association of China-Africa Small-Holder Agriculture (ACASA), Pretoria, South Africa \\ ${ }^{2}$ Faculty of Nursing, Weifang University of Science and Technology, Weifang, China \\ ${ }^{3}$ National Agricultural Marketing Council (NAMC), Pretoria, South Africa \\ ${ }^{4}$ Department of Economics and Governance, North-West University, Potchefstroom Campus, Potchefstroom, \\ South Africa \\ Correspondence: Xiaoshun Qin, Association of China-Africa Small-Holder Agriculture (ACASA), Pretoria, South \\ Africa. Tel: 27-76-829-2606. E-mail: sgqinxiaoshun@gmail.com
}

Received: February 17, $2020 \quad$ Accepted: March 18, $2020 \quad$ Online Published: April 15, 2020

doi:10.5539/jas.v12n5p1 URL: https://doi.org/10.5539/jas.v12n5p1

\begin{abstract}
Since December 2019, the unknown virus was the diagnosis in Wuhan city, Hubei Province, the centre of China, where was been shut down to prevent the outbreak of epidemic on 23 January 2020. As of now, the majority of Chinese people have been self-quarantine at home for more than 25 days. The lack of provision and circulation of agri-product is an essential and indispensable problem for common masses. This article describes the advice and thought of provision and circulation of agri-product under the outbreak of COVID 2019 from six aspects (government, e-business, supermarket, agri-trade market for sale, high-tech delivery as well as rural area or village) in combination of the reality of China to the other country can learn some lesson from Chinese countermeasures to deal with provision and circulation of agri-product under the outbreak of epidemic.
\end{abstract}

Keywords: novel coronavirus, new coronavirus, NCP, agri-production, transport, deliver

\section{Background and Introduction}

Since December 2019, there were several pneumonia cases unknown and unexplained in Wuhan, Hubei Province, center province of China, which were testified to be contracted with Huanan Seafood Wholesale Market where there was also sale of live animals, being confirmed novel coronavirus 2019 (Hui et al., 2020; Qi et al., 2020). The occurrence of concentrated pneumonia cases in Wuhan, Hubei province of China was first reported on December 30, 2019, by the Wuhan Municipal Health Commission (Xu et al., 2020a).

Wuhan, being in the center of China, play one of the most important transport roles in China's transport system (Xu et al., 2020b). The outbreak of epidemic is during the most significant festival in China, the Spring Festival, meaning majority of Chinese would go back to their original home to enjoy festival with their family whom maybe they haven't seen each other for around one year, which brought favourable conditions for the swift and rampant spread of novel coronavirus (Xu et al., 2020b). Especially after Professor Zhongnan Shan visited Wuhan city, he confirmed that there was person-to-person transmission in terms of the novel coronavirus.

In a bid to prevent the novel coronavirus from spreading rapidly and unexpectedly as movement of population due to the Chinese Spring Festival, the whole city of Wuhan has been shut down completely the departure channel at 10:00 on January 23, 2020 (Xu et al., 2020b) including airport, railway, highway, road as well as river channel.

On 20 January 2020, the World Health Organization (WHO) the new virus as 2019 novel coronavirus, namely "2019-nCoV" (Wang, Zhang, Lv, \& Zhou, 2020). Following the delegate committee of WHO lead by Director-general Dr Tedros Adhanom Ghebreyesus visited China in order to know more pertaining to $2019-\mathrm{nCoV}$ and the countermeasure of dealing with this novel coronavirus, WHO announced the New Coronavirus Pneumonia (2019-nCoV) epidemic as a "public health emergency of international concern" on 30 January 2020 and issued interim recommendations simultaneously (Zhang, 2020). On 7 February 2020, the novel 
coronavirus 2019 is named by the Chinese National Health Commission as novel coronavirus pneumonia, (NCP) (Du et al., 2020).

As of 24:00 (Beijing Time) on February 16, according to reports from 31 provinces (autonomous regions, municipalities) and the Xinjiang Production and Construction Corps in China, there were 57,934 confirmed cases of NCP (10,644 of which were severe cases), 10,844 NCP cases of discharged patients were cured, and 1,770 were dead cases. A total of 70,548 confirmed cases were reported, and there were 7,264 suspected cases. A total of 546,016 close contacts were traced, and 150,539 close contacts were still in medical observation in the light of table 1 (Health Emergency Office of National Health Commission, 2020).

Table 1. Update on the epidemic situation of new coronavirus pneumonia as of 24:00 on February 16, 2020 (Health Emergency Office of National Health Commission, 2020)

\begin{tabular}{lllll}
\hline Confirmed Case & Suspected Case & Dead & Close Contact Being Traced & Close Contacts in Medical Observation \\
\hline 70,548 & 7,264 & 1,770 & 546,016 & 150,539 \\
\hline
\end{tabular}

In the following section, the problem statement will be set up in the second chapter, following by advice and countermeasure in the third part. The last part is the conclusion.

\section{Problem Statement}

As mentioned in the previous section, Wuhan city, capital of Hubei province where is the center of China, has been shut down at 10:00 pm local time, on January 23, 2020, because of the outbreak of novel coronavirus 2019 (Xiaoke Xu et al., 2020). More than thirty provinces and Municipalities in China has conducted countermeasure of "first-response" (Chen \& Cao, 2020) on public health due to the person-to-person transmission (Daszak, Olival, \& Li, 2020), severity and extremely damage of NCP, presentation of more people to be contracted. Before lockdown of the city which had around 11 million residents, 5 million of them have left there to join their family or enjoying their holiday, some of whom are a potential carrier of NCP which can be contracted to their family, relatives, friends and so on.

Since 24 January 2020, one day following the lockdown of Wuhan city, the center of outbreak of novel coronavirus and the first day of holiday on Chinese New Year, the community, residents park and complex in Chinese cities, including mega municipality such as Beijing, Shanghai, Guangzhou etc., middle city, for instance, Jinan, Nanjing, Chongqing etc., as well as small city, for example, Shouguang, Suqian and so on, has been shut down and managed by administrators, community public staff and government staff. The residents in these cities can not be allowed to go outside and had to stay at their home for 14 days self-quarantine.

In the rural area, the director, chief, guard and government staff coordinated to shut down the small avenue to the village and put pardon in order to prevent the people who were from Hubei Province, stranger and others from entering into their village. Due to the characteristic of Chinese Spring Festival, Chinese people usually visit their family, relatives and friends between 25 January and 3 February 2020, so it is extremely crucial and urgent to block cross-diagnosis in rural area because small-holder farmers in rural area were lack of knowledge and cognition on novel virus, propaganda and explanation pertaining to NCP, as well as indifference and rebuff of $2019 \mathrm{nCoV}$ (Chen \& Cao, 2020).

Since 24 January 2020, the majority of Chinese people has not gone out in the light of self-quarantine at their home according to the propaganda of novel coronavirus knowledge from government and taking seriously to the new virus. The problem is how they get and obtain nutrient food and vegetable under the influence of the rampant and widespread new coronavirus when people were afraid to go outside for shopping.

In the rural area, the open market is their main source to get their basic food and vegetable which has been cancelled temporally by the local government due to the rampant and uncontrolled NCP. Majority of vegetable from the rural area were gathered in the small agri-trade market and then being sent to the logistics park from where vegetable would be distributed to all over of China. It was difficult and took more time for the small-holder farmer to get to their greenhouse and local agri-trade market in the period of new virus.

Now, the problem is that small-holder farmer is hard to sell their vegetable as usual and customers are not easy to buy multiformity and diversity of fresh and necessary food and vegetable as before the outbreak of new coronavirus in the most cities of China. It is a problem of how to meet the necessity and multiformity of basic food and vegetable for customers. The advice and countermeasure will be given in the next section. 


\section{Advice and Countermeasure}

In the previous chapter, the main problem of this research was elaborated. This section will be focus on the six aspects of advice on provision and circulation of agri-products during the outbreak of new coronavirus.

\subsection{From Perspective of Government}

In first part of this section, six aspects of discussion will be showed as follow:

\subsubsection{Strict Implementation of Local Government Responsibility}

In middle city and small city, the mayor is the principle to be responsible for basic food and vegetable in a bid to oversee the local government to guarantee the provision of basic food and vegetable, such as meat, egg, milk, variety of vegetable as well as seafood and coordinate all aspect and divisions to do their best for all job and tasks including production development, production and sales linkage, circulation and transportation, market regulation, and quality and safety of food and vegetable (MARA, 2020).

It can be guaranteed by the production area that the "vegetable basket" products in the region can be easier to be produced, transported, not backlogged, and not difficult to sell (MARA, 2020). The sales area must actively dock with the production district to ensure the customers in the quarantine area are available to obtain the food and vegetable timely (MARA, 2020).

The local government also used the administrative APP and public hotline in order to deal with the problem swiftly and promptly in stable production and supply of agriculture products.

\subsubsection{Ensure the Production of Vegetable Products}

It is necessary to actively guide large-scale greenhouse CEO, cooperatives and other large-scale business enterprises to carry out mutual assistance cooperation and peak-shift harvesting to solve the problem of difficulty to employ worker, expensiveness of employee as well as cross-infection (MARA, 2020).

The central government and local government ensure to subside the large-scale greenhouse enterprises and artel in a bid to ensure to summon up the worker to return to their position during the period of new coronavirus and holiday.

At the same time, the chief, village staff should elaborate the knowledge of $2019 \mathrm{nCoV}$ and how to protect themselves from being contracted it as well as encourage the small-holder farmers to work as usual in their greenhouse to ensure and warrantee the production of vegetable products.

\subsubsection{Ensure the Smooth Transportation in Road}

It is necessary to implement the "green channel" policy for the transportation of fresh agricultural products and maintain normal market circulation order. It should be included in the spectrum of daily necessities which involved grain and oil, vegetables, meat, eggs, milk, aquatic products and other agricultural products during the epidemic prevention and control (MARA, 2020). In addition to the necessary rapid temperature detection of drivers who deliver the basic food and vegetable, it is strictly implemented by the government to carry out priority and convenient traffic measures for transportation vehicles such as no stopping, no inspection, no toll for the purpose of ensuring quick delivery between different regions.

In the rural area, more and more roads were blocked and destroyed being afraid of new virus spread and protect themselves from the infection of it, nevertheless, it also impedes the transport or trucks from delivering the agricultural production to get to market and nearby supermarket. The government should enact policy to announce it is unappropriated and illicit to block the road and urge the manager of the village to remove the blockage in a bid to ensure the timely, safe, quick and effective conveyance.

\subsubsection{Promote the Circulation of Agricultural Products}

Firstly, in the rural area, the government enact relevant policy which encourages small-holder farmers and cooperative to work in their greenhouse and agri-trade market for sale during the period of outbreak of new coronavirus. It is illegal to prevent the farmers and worker for large-scale ketal from entering their workplace for managing, irrigating, harvesting and selling their vegetable.

Secondary, the government encourage the staff, managers and agri-workers of large-scale cooperatives to come back (Xing \& Fu, 2020) to their position during the holiday of Chinese New Year when the new virus was rampant and widespread all over of China. Central and local government should grant the enterprise fund and policy support which promote and facilitate the activeness of enterprises to restore their agri-production and activity swiftly and quickly. 
Thirdly, the government of provincial level, municipal level and district level should embolden the logistics enterprise to resume the production and transport business as soon as possible as the unrestrained and rampant new coronavirus erupted globally. The government should meet every problem pertaining to the rehabilitation of logistic enterprise as well as they meet when they deliver the agri-product to the destination.

Fourthly, the transport department and relevant department should warrantee the smoothness of village road, district road, provincial road, national road as well as highway and give the priority to agri-product transport and toll-free. Once the blockage on road, the department should contact the relevant responder of division or administration to deal with the problem timely.

Finally, the necessary guarantee and coordination should be provided to agri-products delivery in a bid to transmit to supermarket, agri-trade market and vegetable market mall effectively and efficiently.

\subsubsection{Ensure the Stability of Agricultural Products Price}

When there was a pubic crisis or epidemic outbreak, many entrepreneurs tried their best to obtain the extra- and extreme-profit as the essence and characteristic-perusing-profit of businessman. For example, in a supermarket, one Chinese cabbage, the usual price is around 5-10 CNY, was sold at 63.90 CNY (Bageshelun, 2020) per one which brought pubic anger and outrage among the common folks.

On the other hand, it is extremely difficult and hard to sell their vegetable and agri-products due to the widespread outbreak of novel coronavirus around China. Even if they plan to sell the vegetable and agri-products at extremely and tremendously low price, it is impossible for them to sell.

The reason for stability of agricultural products price is "demand exceeds supply", so the most significant thing is to guarantee the vegetable and agri-products can be sold timely and the smoothness of agri-products transport. The government should coordinate different department, including Department of Trade and Administration, Police Station, Law Enforcement and relevant division, to conduct joint-prevention and joint-control of vegetable and agri-product in order to fight crime and prohibit from driving up the price.

\subsubsection{Strengthen Departmental Coordination and Cooperation}

The government should play a considerable and significant role in joint prevention and joint control in a bid to strengthen departmental collaboration as well as form a joint effort. The policy measures on and agri-products stabilization and supply during the period of epidemic control should be implemented one-hundred percent. Strengthening departmental coordination and cooperation can ensure the supply of residents' necessities and maintain normal and social order.

\subsection{E-Business}

Since 2000, the e-business developed dramatically in China. With the spread of internet users in the following years, the e-business market all over China keeps growing in size. By the end of 2017, the number of internet users in China has reached 772 million which accounted for $55.8 \%$ of the total population ( $\mathrm{Li}$, Sheng, \& Ma, 2018). According to the data of National Bureau of Statistics of China, the transaction volume of e-business in China reached 26.1 trillion yuan (CNY) in 2016 and e-commerce market in China is expected to expand transactions to more than 40 trillion yuan (CNY) by 2020 (Li et al., 2018).

Since December 2019, as the widespread outbreak of new coronavirus all over China, most of the industries, especially shopping, hotel, restaurant, film as well as tourism, were dramatically damaged by the novel virus. The impact on the e-business is relatively small. It can even be said that the Internet industry will directly take part in the market share that originally belonged to traditional industries.

Due to the influence of COVID 2019 which lead to self-quarantine measure or policy, the resident and majority of people were limited at their own home, so daily life requirement was main problem for them. More and more people prefer to buy basic food and vegetable online via different Vegetable-buying APP, such as Hema shengxian, Meituan, Tianmao ChaoShi, Jingdong Daojia (Those are Chinese fresh agri-products e-business) etc. In Figure 1 being collecting from internet knowledge, ten Chinese fresh agri-products E-business APP was demonstrated to show their names, opening time, delivery time as well as whether the price is higher or lower than usual. 


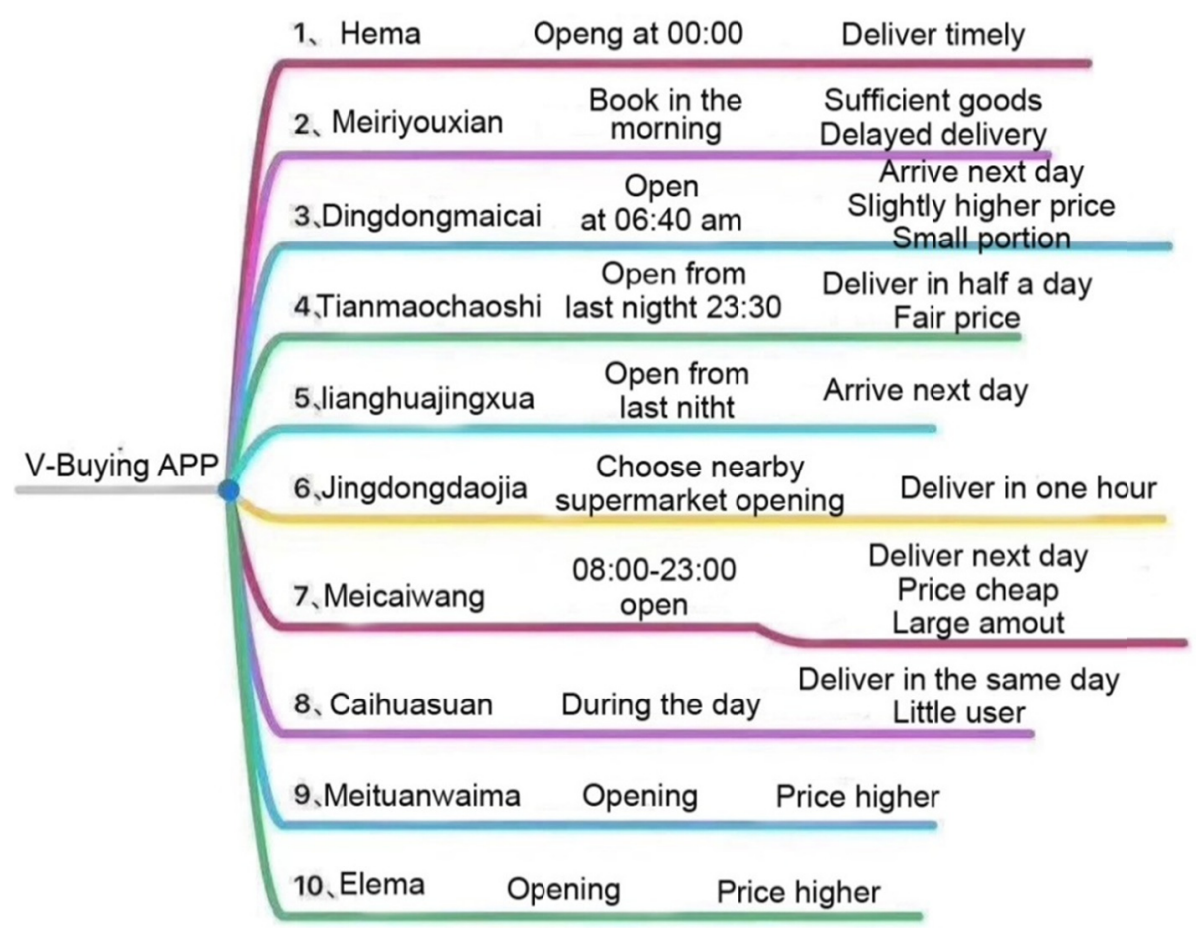

Figure 1. Ten chinese fresh agri-products E-business APP (San, 2020)

For the residents who can't be allowed to go outside for shopping, these agri-products E-business APP can assist the customers to get what they want but not like normal, as some of basic food and vegetable are missing. On the other hand, it is not easy for the elder to buy vegetable online as they don't usually use the smart phone as well as these kinds of E-buying APP. In the future, it is very important to let the elder know how to use this APP to buy basic food and vegetable via smart-phone online on the basis of a young customer remaining unchanged.

In addition to already-existing agri-products e-business, community e-business (Kuang, 2019) is a new model of agri-products e-commerce. In terms of impact on the "uniform distribution" policy of the epidemic outbreak in China, a large number of users have gradually formed a shopping habit of "delivering food to the door", which is very compatible with the buying model of the community group. Due to the influence of new coronavirus, buying habit online has been accepted by the customers who have stayed at their own home more than twenty-five days, so after the new virus community e-commerce will increase in a wave of blowout growth.

\subsection{Supermarket}

In China, supermarket plays an indispensable and essential part (Tan et al., 2018) in daily life and living where the basic living necessities, vegetable, meat, egg, milk and so on can be provided. During the outbreak of novel coronavirus, small supermarkets were shut down by the government for the purpose of safety and unified management. Medium- and large-supermarket were allowed to open in a bid to guarantee the life necessities and fresh, par vegetable.

Some of the supermarkets have developed their own APP via which the life necessity and fresh vegetable can be sold at par. Others collaborated with agri-products e-business enterprise or logistics corporation to deliver the vegetable to customers' door.

Under the outspread of the novel coronavirus, CEOs and managers of supermarket should stimulate the staff to come back to their position (Xing \& Fu, 2020) so as to guarantee the provision, running, operation of supermarket. The necessary disinfection, checking, protection as well as the knowledge of novel coronavirus should be conduct frequently and timely. In the light of extremely demanding online, the staff at the supermarket should collect, package, deliver timely to ensure the customer to get their commodity on schedule.

\subsection{Agri-trade Market for Sale}

Apart from the supermarket, the agri-trade market for sale in China is another source for customers to buy their life necessities and vegetable (Hong, 2019) in the city of China. The Wuhan Huanan seafood market was associated to the novel coronavirus and official from central government and some professors confirmed that 
new virus was linked to the wild animal, so many agri-trade markets were closed for disinfection, checking and rectification.

The agri-trade market for sale is essential and indispensable for local people living in the city where they can buy life necessities, vegetable, seafood, meat (Hong, 2019) and milk and so on. The relevant department, such as the Division of Industry and Administration and Division of Health Commission, should embolden small-business in this market to resume their business if the condition of health, disinfection and protection are fine. It is crucial and significant to provide necessary masks and teach them knowledge on how to avoid cross-infection and to protect themselves.

It is important to encourage the small-business man to do the business off-peak. The customer should be in the queue for a long distance between two people. Customers and owner of small-business who enter the entry and go outside should be checked the temperature. If the body temperature of someone is abnormal, the people should be sent to the hospital as soon as possible and furthermore, the relevant person who contacted him or her should be quarantined immediately.

\subsection{High-Tech Delivery}

In the period of epidemic outbreak, high-tech delivery equipment (Xiang, 2020; Anonymous, 2020) should be employed in the process of basic necessity and vegetable transport. Unmanned self-driving vehicle (Xiang, 2020) should be set up the software to deliver the vegetable to the door or the building of the customer. Because it unlinked to the customer, there was no cross-infection and contact-infection and it is a safe and innovation delivery way.

In some area, drone becomes safe and convenient transport equipment for seller and customer to deliver the commodity (Anonymous, 2020). The load capacity of general drones is mostly between $0-25 \mathrm{KG}$, so it is not a problem for the drone to air ferry the merchandise (Anonymous, 2020). Nevertheless, the only problem is that skilled drone operators are not enough and sufficient. In the future, especially when there is an outbreak of epidemic or major public safety incident, customers and sellers will not only buy or sell the life necessities and vegetables but also become drone operators as well.

\subsection{Rural Area or Village}

In the rural area or village in China, it is not a big problem for them who plant, manage and harvest the vegetable by themselves. The people from the rural area have inherited the excellent tradition of diligence and saving of the Chinese nation, especial for the old generation who went through the period of starvation and hardship. Furthermore, in the rural area, people are relatives, friend and classmate who always help each other, so they can exchange the vegetable that they have.

For the younger generation in the village or rural area, it is easy for them to get the internet and online skill. The vegetable can be bought and sold via WeChat group in which there are around 500 people inside. They have many of these kinds of WeChat groups, so it is easier for them to get what they want via this software in the nearby area. There are so many young people conducting this kind of business that WeChat users buy the different sorts of vegetable from small-holder farmers, packing at their home and deliver to the customer using their electric car or petrol car.

In short, the suggestion from six aspects has been elaborated to advise provision and circulation of agri-product during the outbreak of novel coronavirus which the epicenter is in Wuhan, Hubei province. The next chapter is conclusion.

\section{Conclusion}

Since the closedown of the Wuhan City of China, twenty-seven days have been passed. Majority of Chinese folks are still staying their home for the second 14-days self-quarantine in a bid to support their countries and not to make any trouble for their mother-countries.

There were many problem and dilemma pertaining to provision and circulation of agri-product at the beginning of the outbreak of novel coronavirus when it was also the holiday of Chines New year. As government, businessman, supermarket, agri-trade market and logistic enterprise involved in the struggle to provide the basic necessities and kinds of vegetable, the problem of provision and circulation of agri-product would be met.

This article describes the advice and thought of provision and circulation of agri-product under the outbreak of COVID 2019 from six aspects in a combination of the reality of China so as to the other country can learn some lesson from Chinese countermeasures to deal with provision and circulation of agri-product under the outbreak of the epidemic. 


\section{Limitation and Future Research}

This article is only to explain the six aspects of how to deal with provision and circulation of agri-product amid the outbreak of COVID 2019 in a combination of the reality of China. This is only the author's advice and thought. There are no data to support the research. In the future, the study with methodology and data will be prepared to support our view.

\section{References}

Anonymous. (2020). How can artificial intelligence help to fight the Covid-19? (pp. 1-2). Post \& Telecom Press, China. https://doi.org/10.28659/n.cnki.nrmyd.2020.000396

Bageshelun. (2020). Chinese cabbage price skyrocket. Retrieved from https://baijiahao.baidu.com/s?id=1656 $889892284965998 \& w f r=$ spider\&for $=$ pc

Chen, Y., \& Cao, G. (2020). Incidence trend of novel coronavirus (SARS-Co V-2)-infected pneumonia in China. Shanghai Journal of Preventive Medicine, 32(2), 1-6. https://doi.org/10.19428/j.cnki.sjpm.2020.20053

Daszak, P., Olival, K. J., \& Li, H. (2020). A strategy to prevent future epidemics similar to the 2019-nCoV outbreak. Biosafety and Health, in press. https://doi.org/10.1016/j.bsheal.2020.01.003

Du, Y., Jin, C., Yang, J., Chen, T., Zhang, X., Zhang, D., ... Guo, Y. (2020). Clinical features and CT signs of early family clustering novel coronavirus pneumonia. Journal of Xi'an Jiaotong University (Medical Sciences), 1-7. Retrieved from http://kns.cnki.net/kcms/detail/61.1399.r.20200213.0838.004.html

Health Emergency Office of National Health Commission. (2020). Update on the epidemic situation of new coronavirus pneumonia as of 24:00 on February 18, 2020. Retrieved from http://www.nhc.gov.cn/ $\mathrm{xcs} / \mathrm{yqtb} / 202002 / 18546 \mathrm{da} 875 \mathrm{~d} 74445 \mathrm{bb} 537 \mathrm{ab} 014 \mathrm{e} 7 \mathrm{a} 1 \mathrm{c} 6 . \mathrm{shtml}$

Hong, L. (2019). What is the healthy development of the rural market? Modern Logistics (p. 1). https://doi.org/10.28842/n.cnki.nwzxx.2019.000121

Hui, D. S., Azhar, E. I., Madani, T. A., Ntoumi, F., Kock, R., Dar, O., ... Drosten, C. (2020). The continuing 2019-nCoV epidemic threat of novel coronaviruses to global health-The latest 2019 novel coronavirus outbreak in Wuhan, China. International Journal of Infectious Diseases, 91, 264-266. https://doi.org/ 10.1016/j.ijid.2020.01.009

Kuang, Y. (2019). Analysis of the status and trends of community e-commerce development. China Collective Economy, 33, 56-57.

Li, L., Sheng, X., \& Ma, L. (2018). E-business Research in China over the Last Two Decades: A Bibliometric Analysis of Projects Granted by National Social Science Fund of China. PACIS, 1-8.

MARA. (2020). Notice of State Council on Compacting Mayor Responsible System of "Vegetable Basket" and Steady Production and Guarantee of Agri-products in Order to Against New Coronavirus. Retrieved from http://www.gov.cn/xinwen/2020-02/13/content_5477980.htm

Qi, Y., Chen, L., Zhang, Y., Yang, Y., Zhan, S., \& Fu, C. (2020). Deal with 2019 Novel Coronavirus (2019-nCoV) under New Situation, Prevention and Control are More Important. Journal of Tropical Medicine, 1-12. Retrieved from http://kns.cnki.net/kcms/detail/44.1503.R.20200204.1114.002.html

San, J. (2020). Thought on the e-commerce industry under the epidemic situation. Retrieved from https://36kr.com $/ \mathrm{p} / 5293100$

Tan, P. J., Corsi, A., Cohen, J., Sharp, A., Lockshin, L., Caruso, W., \& Bogomolova, S. (2018). Assessing the sales effectiveness of differently located endcaps in a supermarket. Journal of Retailing and Consumer Services, 43, 200-208. https://doi.org/10.1016/j.jretconser.2018.03.015

Wang, Y., Zhang, N., Lv, H., \& Zhou, Y. (2020). Preliminary Analysis on the Incidence Trend of Novel Coronavirus (2019 nCoV)-infected Pneumonia in Shanghai. Shanghai Journal of Preventive Medicine, 32(02), 166-170. https://doi.org/10.19428/j.cnki.sjpm.2020.20041

Xiang, L. (2020). Anti-Covid-19 boosts technological innovation. Global Times. https://doi.org/10.28378/ n.cnki.nhqsb. 2020.001258

Xing, C., \& Fu, M. (2020). The epidemic prevention and control isolation should change. Global Times. https://doi.org/10.28378/n.cnki.nhqsb.2020.001641 
Xu, X., Chen, P., Wang, J., Feng, J., Zhou, H., Li, X., ... Hao, P. (2020b). Evolution of the novel coronavirus from the ongoing Wuhan outbreak and modelling of its spike protein for risk of human transmission. Science China Life Sciences, 1-4. https://doi.org/doi.org/10.1007/s11427-020-1637-5

Xu, X., Wen, C., Zhang, G., Sun, H., Liu, B., \& Wang, X. (2020a). The Geographical Destination on Distribution and Effet of Outflow Population of Wuhan When the Outbreak of the 2019-nCoV Pneumonia. Journal of University of Electronic Science and Technology of China, 1-6. Retrieved from http://kns.cnki.net/kcms/detail/51.1207.T.20200213.2002.002.html

Zhang, H. (2020). Ethical Reflections for Conducting 2019-nCoV Related Research During the Public Health Emergency. Chinese Medical Ethics.

\section{Copyrights}

Copyright for this article is retained by the author(s), with first publication rights granted to the journal.

This is an open-access article distributed under the terms and conditions of the Creative Commons Attribution license (http://creativecommons.org/licenses/by/4.0/). 